\title{
Light Intensity Influences Photosynthesis and Crop Characteristics of Jeffersonia dubia
}

\author{
Yong Ha Rhie ${ }^{1}$, Seung Youn Lee ${ }^{1}$, Hyun Hwan Jung ${ }^{1}$, and Ki Sun Kim ${ }^{1,2 *}$ \\ ${ }^{1}$ Department of Horticultural Science \& Biotechnology, Seoul National University, Seoul 151-921, Korea \\ ${ }^{2}$ Research Institute of Agriculture and Life Sciences, Seoul National University, Seoul 151-921, Korea
}

\begin{abstract}
Jeffersonia dubia is a spring-flowering perennial found in rich forests in Korea and Northern China and has potential as an ornamental or medicinal plant. However, illegal picking and land use change have decreased the number of populations and overall population size of this plant in its natural habitat. Although J. dubia has been reported to be a shade-preferring plant, no study has determined the optimum light intensity for its growth. The objectives of this work were to observe the effects of various shading levels on the physiological responses of $J$. dubia and to determine the proper shading level for cultivation. Treatments consisted of four shading levels $(0 \%, 50 \%, 75 \%$, and $95 \%$ shade) imposed using black mesh cloth. The number of leaves and dry weight increased with decreased shading. The shoot-to-root ratio increased with increased shading, mainly due to decreased root dry weight under shading. Plants showed low net $\mathrm{CO}_{2}$ assimilation rates and $\mathrm{F}_{\mathrm{v}} / \mathrm{F}_{\mathrm{m}}$ values combined with low dry matter levels when grown under $0 \%$ shade (full sunlight). These results indicate that $J$. dubia plants experience excessive irradiance without shading, resulting in damage to the photosynthetic apparatus. By contrast, the net photosynthesis rate increased as the shading level increased. $F_{v} / F_{m}$, the potential efficiency of PSII, was 0.8 under $95 \%$ shade, indicating that J. dubia is well-adapted under heavy shading. However, the low dry matter of plants in the $95 \%$ shade treatment indicated that the low light intensity under $95 \%$ shade led to a decline in plant growth. Thus, moderate light (50\% shading) is recommended for cultivating $J$. dubia without physiological defects.
\end{abstract}

Additional key words: chlorophyll fluorescence, dry matter accumulation, net $\mathrm{CO}_{2}$ assimilation rate, photoinhibition, shading

\section{Introduction}

Plants in the field are permanently exposed to various environmental conditions such as light, soil water content, temperature, and soil nutrients. Among these, light intensity is one of the most important plant growth requirements. Light energy is used to produce ATP and NADPH in the light reactions of photosynthesis (Taiz and Zeiger, 2007). Subsequently, the consumption of ATP and NADPH is coupled to reactions in which the reduction of $\mathrm{CO}_{2}$ to carbohydrates is catalyzed by a light-independent reaction. Under high irradiance, however, the photosynthetic apparatus absorbs excessive light energy, causing the inactivation or impairment of the chlorophyll-containing reaction centers of the chloroplasts (Bertamini et al., 2006). As a consequence, photosynthetic activity is hindered by photoinhibition (Osmond, 1994). Alternatively, under low irradiance, ATP is too limited to allow for carbon fixation and carbohydrate biosynthesis. This leads to decreased plant growth and development (Dai et al., 2009).

Jeffersonia dubia (Maxim.) Benth. \& Hook. f. ex Baker $\&$ S. Moore (Berberidaceae) is a herbaceous perennial native to Korea. It is distributed in Northeastern Asia and ranges from Southern Korea to Northeast China and Eastern Siberia (Hutchinson, 1920). J. dubia blooms in early spring and has showy light purple flowers and attractive heart-shaped leaves. Thus, it has potential as a new ornamental crop for gardens (Huang, 1995). J. dubia has value not only

\footnotetext{
*Comesponding author: kisun@snu.ac.kr

※ Received 20 February 2014; Revised 14 April 2014; Accepted 29 April 2014. This research was supported by the Korea Institute of Planning and Evaluation for Technology of Food, Agriculture, Forestry and Fisheries. Project No. 109096-5.

(C) 2014 Korean Society for Horticultural Science
} 
as an ornamental plant, but also when used for medicinal purposes. It has also been used in Korean folk medicine as an antidote and stomachic (Bae, 2000). Extracts of $J$. dubia roots have berberine, which has been identified as a promising cholesterol-lowering drug that acts through different pathways than those of statins (Kong et al., 2004). However, because of extensive collection and changes in land usage, the total number and size of the populations are decreasing. One of the problems for producing J. dubia is the long cultivation period; the plant takes at least three years to bloom after sowing.

Although J. dubia has been reported to be well adapted to shade ( $>90 \%$ shade of incident sunlight), because plants grow naturally in deciduous forests (NIER, 2004), we assume that $J$. dubia has a long cultivation period because of the lack of light in a rich forest. There is limited information on the effect of shading on the growth and physiological response of $J$. dubia. Thus, the objectives of this work are to observe the effects of various shading on photosynthesis, chlorophyll fluorescence, and growth of J. dubia, and to determine the proper shading level.

\section{Materials and Methods}

\section{Plants and Growth Conditions}

One-year old $J$. dubia plants were collected from an ex situ conservation habitat of the Korea Botanic Garden in Pyeongchang, Gangwon, Korea ( $\left.37^{\circ} 37^{\prime} \mathrm{S}, 128^{\circ} 39^{\prime} \mathrm{E}\right)$ and planted on 31 Mar. 2009. Plants were planted in 10-cm pots containing a mixture of peat, perlite, and sand (4:1:5), and grown in a greenhouse under natural light conditions. Three treatments were considered, with 50, 75, and 95\% shade nets erected horizontally above the plants, while unshaded plants were used as a control ( $0 \%$ shade). Screens were positioned $1 \mathrm{~m}$ high, about $0.8 \mathrm{~m}$ above the canopies. The experiments were conducted in a greenhouse located at the experimental farm of Seoul National University, Suwon, Korea $\left(37^{\circ} 27^{\prime} S, 126^{\circ} 99^{\prime} \mathrm{E}\right)$, from 3 Apr. 2009 to 31 Jul. 2009. We measured the diurnal variation of photosynthetic photon flux density (PPFD) on 1 April under each treatment with a Pyranometer (LI-1400, Li-Cor, Lincoln, NE, USA) and recorded air temperature at 1-hour intervals with a thermo data logger (Watch Dog Model 450, Spectrum Technologies, Inc., Plainfield, IL, USA). Irrigation was provided manually to saturation at 09:00 AM every day. Slow-release fertilizer $\left(23 \mathrm{~N}-6 \mathrm{P}-17 \mathrm{~K}, 43.5 \mathrm{~g} \cdot \mathrm{m}^{-2}\right.$, Haifa Chemicals Ltd., Haifa Bay, Israel) was applied once after planting.

\section{Growth Parameters}

Plant height, leaf length and width, number of leaves, and dry matter partitioning were measured at 15 weeks after treatment. At the end of the experiment, the shoots and roots of each plant were immediately dried at $80^{\circ} \mathrm{C}$ in an oven for 72 hours in order to measure dry weight.

\section{Photosynthetic Parameters}

Net $\mathrm{CO}_{2}$ assimilation rates $(A)$ were determined using a LI-6400 portable photosynthesis system (Li-Cor, Lincoln, NE, USA) after 40 days of treatment (18 June 2009). The parameters were measured on fully expanded leaves from 09:00 to 17:00 hours on 18 Jun. 2009. The leaf chamber temperature and the $\mathrm{CO}_{2}$ concentration were maintained at $25^{\circ} \mathrm{C}$ and $400 \mu \mathrm{mol} \cdot \mathrm{CO}_{2} \cdot \mathrm{mol}^{-1} \cdot \mathrm{s}^{-1}$, respectively. PPFD was increased from 0 to $1500 \mu \mathrm{mol} \cdot \mathrm{m}^{-2} \cdot \mathrm{s}^{-1}(0,20,50,100$, $300,500,1000$, and $\left.1500 \mu \mathrm{mol} \cdot \mathrm{m}^{-2} \cdot \mathrm{s}^{-1}\right) . A$ was recorded at each of the seven light levels following a 10-minute acclimation period.

\section{Chlorophyll Fluorescence}

Chlorophyll fluorescence was determined during the day. Leaves were dark-adapted for 30 minutes before measurements were taken using leaf clips. Between 10:00 $\mathrm{AM}$ to 11:00 AM, the emitted fluorescence was recorded for the dark-adapted leaves with a portable pulse amplitude modulation fluorometer (PAM-2000, Walz, Effeltrich, Germany). A measuring light of $0.6 \mathrm{kHz}$ and less than $0.1 \mu \mathrm{mol} \cdot \mathrm{m}^{-2} \cdot \mathrm{s}^{-1}$ PPFD was irradiated to obtain the minimum fluorescence in the dark-adapted state $\left(\mathrm{F}_{0}\right)$, and then a saturating light pulse at about $8000 \mu \mathrm{mol} \cdot \mathrm{m}^{-2} \cdot \mathrm{s}^{-1} \mathrm{PPFD}$ was irradiated for $0.8 \mathrm{~s}$ to induce the maximum fluorescence in the darkadapted stated $\left(\mathrm{F}_{\mathrm{m}}\right)$. Potential quantum yields in the darkadapted states were estimated from $\left(\mathrm{F}_{\mathrm{m}}-\mathrm{F}_{0}\right) / \mathrm{F}_{\mathrm{m}}=\mathrm{F}_{\mathrm{v}} / \mathrm{F}_{\mathrm{m}}$ representing the efficiency of energy captured by open PSII (Genty et al., 1989). Chlorophyll fluorescence was measured on 12 May and 29 Jun., 2009, respectively.

\section{Data Analysis}

Experiments were conducted in a completely randomized block design with 22 plants per treatment. Collected data were analyzed by analysis of variance (ANOVA) following the general linear model procedure, SAS 9.1 (SAS Institute Inc., Cary, USA). Analysis and graph module were made using Sigma Plot 10.0 (SPSS, Inc., Chicago, USA). When significant differences were found, the means were separated using Duncan's multiple range test at the 5\% level. 


\section{Results and Discussion}

The PPFD level was reduced by the utilization of black mesh cloth. Compared to the $0 \%$ shade treatment, the

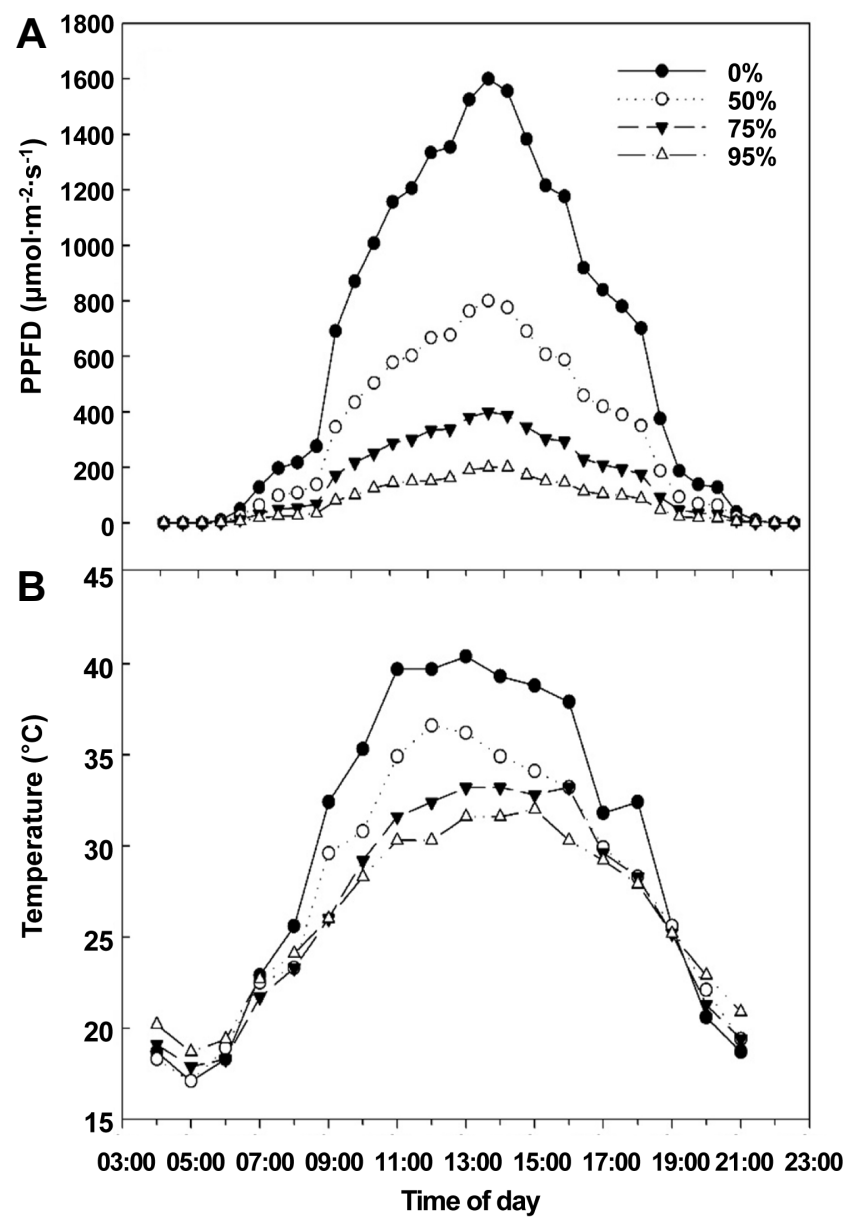

Fig. 1. Diurnal change of canopy PPFD (A) and air temperature (B) under different shading levels in a greenhouse on 1 Apr. 2009 in Suwon, Korea.
PPFD level was reduced by $50.6,74.5$, and $95.9 \%$ in the 50,75 , and $95 \%$ shade treatments, respectively, at 12:30 on a sunny day in the greenhouse (Fig. 1A). Shading also led to a decrease in the air temperature. During the hottest hours (11:00-13:00 hours), air temperatures under 50, 75 , or $95 \%$ shade were approximately 4,8 , or $12^{\circ} \mathrm{C}$ lower than those under $0 \%$ shade, respectively (Fig. 1B).

Plants grown under $75 \%$ and $95 \%$ shade were $1-2 \mathrm{~cm}$ taller than plants from the other treatments $(0$ and $50 \%$ shade) (Table 1). Under shaded conditions, the plant height, shoot length, and flower stem length were also increased compared to unshaded conditions in Hibiscus syriacus L. (Yoo and Kim, 1997), Hydrangea serrata for. acuminate (Lee et al., 2008), lily (Sorrentino et al., 1997), and ferns (You et al., 2005), indicating that plants show a shade avoidance response under shaded conditions. Shading had no significant effects on leaf length and width. However, the number of leaves and dry weight were affected by the shade treatments (Table 1). Plants treated with $0 \%$ and $50 \%$ shade produced more leaves compared with $75 \%$ and $95 \%$ shade treated plants. The dry weights of shoots and roots under $50 \%$ shade were $187 \%$ and $420 \%$ higher than those under 95\% shade, respectively (Table 1 and Fig. 3). The shoot:root ratio was increased with increasing shading rate. Under $95 \%$ shade, the shoot:root ratio was 0.97 , two times higher than the 0 or $50 \%$ shade treatments. In Rhamnus alaternus, a decrease in light induces an increasing shoot:root ratio, and this phenomenon was explained by a reduction in evaporative demand due to shading, affecting the water absorption needs, which possibly diminished the root growth (Miralles et al., 2011).

Regardless of the shading treatment, the net $\mathrm{CO}_{2}$ assimilation rates $\left(A_{n}\right)$ increased rapidly as PPFD increased to 150 $\mu \mathrm{mol} \cdot \mathrm{m}^{-2} \cdot \mathrm{s}^{-1}$, increasing slowly to a maximum, followed by a slow decrease as PPFD was increased to $2000 \mathrm{\mu mol} \cdot \mathrm{m}^{-2} \cdot \mathrm{s}^{-1}$ (Fig. 2). A PPFD higher than the saturation point for photo-

Table 1. Effects of shading on the growth of Jeffersonia dubia at 15 weeks after treatment.

\begin{tabular}{lccccccc}
\hline $\begin{array}{l}\text { Shading } \\
(\%)\end{array}$ & $\begin{array}{c}\text { Plant height } \\
(\mathrm{cm})\end{array}$ & $\begin{array}{c}\text { Leaf length } \\
(\mathrm{cm})\end{array}$ & $\begin{array}{c}\text { Leaf width } \\
(\mathrm{cm})\end{array}$ & \multicolumn{2}{c}{$\begin{array}{c}\text { No. of } \\
\text { leaves }\end{array}$} & & \multicolumn{2}{c}{ Dry weight $(\mathrm{g})$} & \multirow{2}{*}{$\begin{array}{c}\text { Shoot:root } \\
\text { ratio }\end{array}$} \\
\hline 0 & $7.6 \mathrm{~b}^{\mathrm{z}}$ & $1.7 \mathrm{a}$ & $3.4 \mathrm{a}$ & $5.5 \mathrm{~b}$ & $0.219 \mathrm{ab}$ & $0.521 \mathrm{a}$ & 0.42 \\
50 & $7.7 \mathrm{~b}$ & $1.8 \mathrm{a}$ & $3.5 \mathrm{a}$ & $5.6 \mathrm{~b}$ & $0.288 \mathrm{a}$ & $0.664 \mathrm{a}$ & 0.43 \\
75 & $9.1 \mathrm{a}$ & $1.9 \mathrm{a}$ & $3.4 \mathrm{a}$ & $3.8 \mathrm{a}$ & $0.240 \mathrm{a}$ & $0.309 \mathrm{~b}$ & 0.78 \\
95 & $9.9 \mathrm{a}$ & $2.0 \mathrm{a}$ & $3.8 \mathrm{a}$ & $3.6 \mathrm{a}$ & $0.154 \mathrm{~b}$ & $0.158 \mathrm{~b}$ & 0.97 \\
Significance & $* * *$ & $\mathrm{~ns}$ & $\mathrm{~ns}$ & $* * *$ & $*$ & $* * *$ & \\
\hline
\end{tabular}

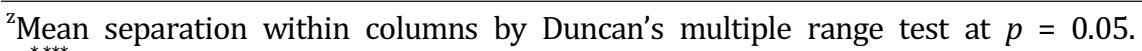

ns, ${ }^{* * * *}$ Non-significant or significantly different at $p=0.05$ or 0.001 , respectively. 
synthesis induces non-radiative de-excitation mechanisms at the chlorophyll level in the PSII complexes, resulting in a decreased maximum quantum yield of photosynthesis (Pastenes et al., 2003). The light compensation points (LCPs) in $0 \%$ shade treated plants were slightly higher than

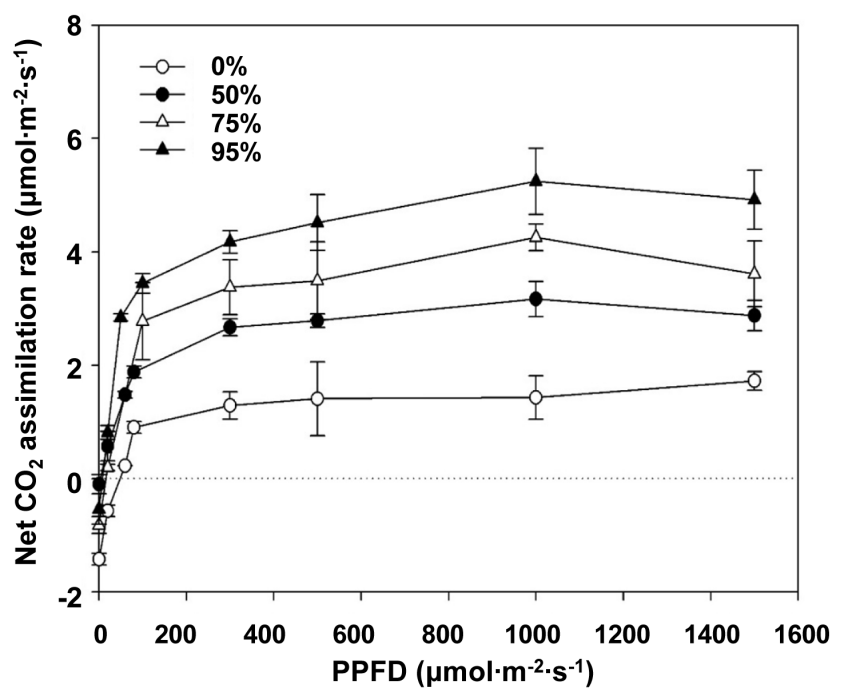

Fig. 2. Net $\mathrm{CO}_{2}$ assimilation rate curves from leaves of Jeffersonia dubia under different shading levels in a greenhouse on 18 Jun. 2009. Vertical bars represent standard errors of the means. those of the $50 \%, 75 \%$, and $95 \%$ shade-treated plants. It was also reported that Guzmania monostachia damaged by high light intensities had increased LCPs (Maxwell et al., 1992), indicating that J. dubia was also injured by high light intensities under $0 \%$ shade. Both $A_{n}$ and maximum $A_{n}$ varied significantly $(p<0.05)$ among the light intensity treatments. The maximum $A_{n}$ under $0,50,75$, and $95 \%$ shade was approximately $1.9,2.9,3.7$, and $4.7 \mu \mathrm{mol} \mathrm{CO}_{2} \cdot \mathrm{m}^{-2} \cdot \mathrm{s}^{-1}$, respectively. High light intensity causes a decrease in the rate of PSI-mediated electron transport (Reichenauer et al., 1997), and it is linearly related with inhibition of PSII photochemistry (Long et al., 1994). These results indicate some degree of decline of photosynthetic capacity under high light above $95 \%$ shade.

The combination of high light and high temperatures can also affect photosynthetic efficiency (Barber and Andersson, 1992), leading to photoinhibition (Demmig-Adams, 1990), which can be measured by chlorophyll a fluorescence. A very good correlation has been observed between photoinhibition and a decreased ratio of variable to maximum fluorescence, i.e., the $F_{v} / F_{m}$ ratio (Bolhar-Nordenkampf and Öquist, 1993). The $F_{v} / F_{m}$ parameter has been correlated with the maximum quantum yield of photosynthesis (Björkman and Demmig-Adams, 1987; Bolhar-Nordenkampf and Öquist, 1993; Cornic and Briantais, 1991), reaching a maximum

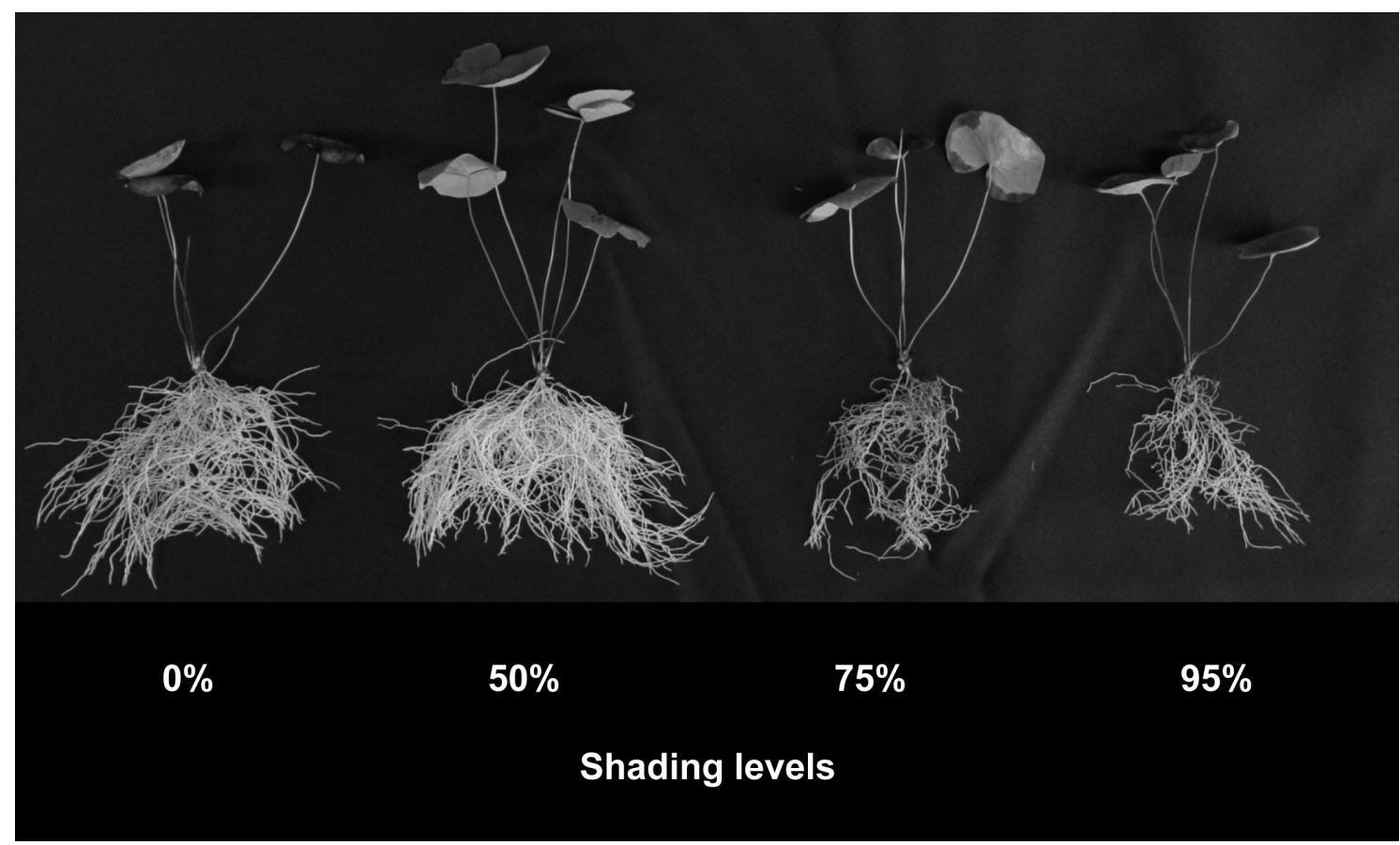

Fig. 3. Photograph showing the growth of Jeffersonia dubia under different shading levels in a greenhouse at 15 weeks after treatment. 


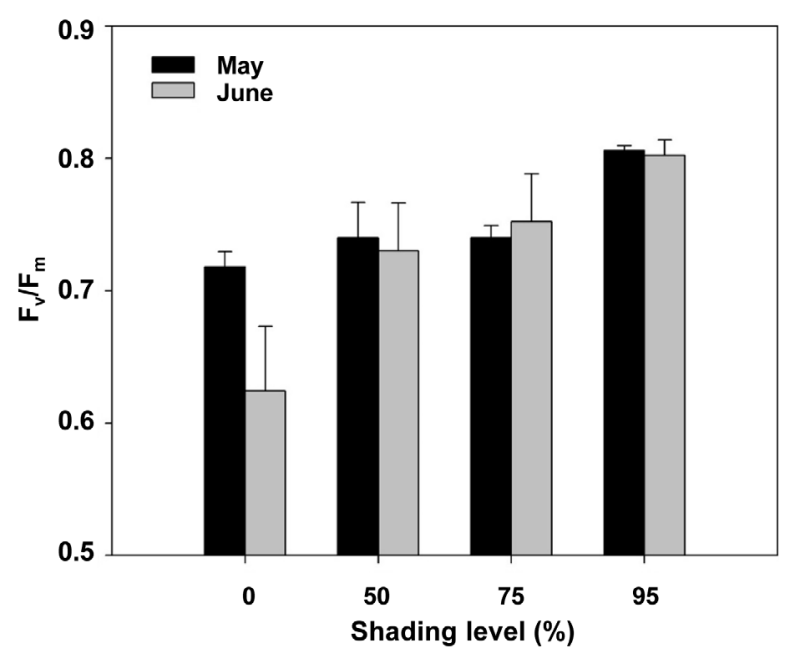

Fig. 4. Changes in the maximum quantum efficiency $\left(\mathrm{F}_{\mathrm{v}} / \mathrm{F}_{\mathrm{m}}\right)$ of Jeffersonia dubia on 12 May and 29 Jun. 2009 under 0, 50, 75, and 95\% shade levels. Vertical bars represent standard errors of the means.

theoretical value of 0.85 (Bolhar-Nordenkampf et al., 1991). Fluorescence measurements were performed on 12 May and 29 Jun. 2009. In $95 \%$ shade, $F_{v} / F_{m}$ values remained near the optimal values of 0.8 for both dates, indicating that the heavy shading was effective in preventing photoinhibition.

Therefore, this shade-tolerant plant could adapt to grow under a light intensity of $>90 \%$ shade in nature, and such high $A_{n}$ and $\mathrm{F}_{\mathrm{v}} / \mathrm{F}_{\mathrm{m}}$ were shown under this low light intensity condition. On the other hand, a decrease in the $F_{v} / F_{m}$ value indicated photoinhibition in the 0,50 , and $75 \%$ shade treated plants. Under 50 and $75 \%$ shade, the $F_{v} / F_{m}$ value declined moderately, holding steady in both May and June. However, exposure to the high irradiance conditions of the $0 \%$ shade treatment resulted in a greatly reduced $\mathrm{F}_{\mathrm{v}} / \mathrm{F}_{\mathrm{m}}$ value, which was apparent in June. Under $0 \%$ shade, the $F_{v} / F_{m}$ value was $0.72 \pm 0.01$ in May and $0.62 \pm 0.05$ in June, showing severe chronic photoinhibition of photosynthesis.

This kind of photoinhibition causes a decrease in photosynthetic efficiency, and may lead to limitations in daily carbon gain with a lower capacity for plant dry mass accumulation (Ögren and Sjöström, 1990). In this study, the dry weight of the shoots and roots under $0 \%$ shade was $24 \%$ and $22 \%$ lower than that under the $50 \%$ shade (Table 1). In Tetrastigma hemsleyanum, the low rate of electron transport through PSII and the high non-photochemical quenching of chlorophyll fluorescence values combined with unhealthy leaf morphology (smaller leaf size and yellow leaf color), as well as the low $A_{n}$ of the plants grown under high light intensity suggested that excess light energy damaged the plants (Dai et al., 2009). This is thought to be due to the formation of destructive oxidative molecules, resulting in damage to the photosynthetic apparatus via photoinhibition (Aro et al., 1993; Krause, 1988). Shading resulted in lower air temperature compared to $0 \%$ shade treated plants throughout the day (Fig. 1B). Leaf temperature increases cause increased susceptibility to photoinhibition (Gamon and Pearcy, 1990). Similarly, decreases in the $\mathrm{F}_{\mathrm{v}} / \mathrm{F}_{\mathrm{m}}$ value in the $0 \%$ shade treatment were probably dependent on PPFD levels associated with high temperatures.

According to the value of $A$ and $\mathrm{F}_{\mathrm{v}} / \mathrm{F}_{\mathrm{m}}$, the photosynthetic ability of $J$. dubia was the best when plants were grown under $95 \%$ shade. This characteristic might allow J. dubia to be used as indoor plants. However, 95\% shade-treated plants had the lowest dry weight of the shoots and roots, whereas the $50 \%$ shade had the greatest (Table 1). These results indicated that a light intensity under $95 \%$ shade led to diminished production of carbohydrates. At low light intensities (below the light saturation point), the rate of photosynthesis increases proportionately as the light intensity increases. However, under 95\% shade, the light coming through the shade cloth was quite low, below 100 $\mu \mathrm{mol} \cdot \mathrm{m}^{-2} \cdot \mathrm{s}^{-1}$ PPFD on a sunny day (Fig. $1 \mathrm{~A}$ ). The light saturation point of plants grown under $95 \%$ shade was around $1000 \mathrm{\mu mol} \cdot \mathrm{m}^{-2} \cdot \mathrm{s}^{-1}$ PPFD (Fig. 2).

\section{Conclusions}

Shading levels significantly affected the growth of $J$. dubia. Plant growth (dry matter and number of leaves) was optimal when plants were grown under $50 \%$ shade. With high light intensity under $0 \%$ shade, photosynthetic activity was depressed, likely due to photoinhibition. On the other hand, light intensity reductions greater than that due to $75 \%$ shade resulted in irradiation insufficient to maintain $A_{n}$, influencing carbon balance and consequently leading to a decline in plant growth. Thus, approximately $50 \%$ shade is concluded to be the optimum light irradiance condition for $J$. dubia cultivation. In view of the low light acclimation capacity of this plant, wild J. dubia is not expected to occur in the shaded understory where the light intensity is greater than $50 \%$ of ambient values. The light intensity of natural habitat areas with less than that coming from $10 \%$ ambient light will decrease the productivity of $J$. dubia. For agricultural purposes, in order to obtain high yields of $J$. dubia, we recommend trying to achieve approximately $50 \%$ ambient light with a shade net, which reduces incident PPFD and leaf temperatures. 


\section{Literature Cited}

Aro, E.M., I. Virgin, and B. Andersson. 1993. Photoinhibition of photosystem II. Inactivation, protein damage and turnover. Biochim. Biophys. Acta 1143:113-134.

Bae, K. 2000. The medicinal plants of Korea. Kyo-Hak Publishing Co., Seoul.

Barber, J. and B. Andersson. 1992. Too much of a good thing: Light can be bad for photosynthesis. Trends Biochem. Sci. 17:61-66.

Bertamini, M., K. Muthuchelian, M. Rubinigg, R. Zorer, R. Velasco, and N. Nedunchezhian. 2006. Low-night temperature increased the photoinhibition of photosynthesis in grapevine (Vitis vinifera L. cv. Riesling) leaves. Environ. Expt. Bot. 57:25-31.

Björkman, O. and B. Demmig-Adams. 1994. Regulation of photosynthetic light energy capture, conversion and dissipation in leaves of higher plants, p. 17-47. In: E.-D. Schulze and M.M. Caldwell (eds.). Ecophysiology of photosynthesis. Springer, Berlin.

Bolhar-Nordenkampf, H., M. Hofer, and E. Lechner. 1991. Analysis of light-induced reduction of the photochemical capacity in field-grown plants. Evidence for photoinhibition? Photosyn. Res. 27:31-39.

Bolhar-Nordenkampf, H.R. and G. Öquist. 1993. Chlorophyll fluorescence as a tool in photosynthesis research, p. 193-206. In: D.O. Hall, I.M.O. Scurtock, H.R. Bolhar-Nordenkampf, R.C. Leegood, and S.P. Long (eds.). Photosynthesis and production in a changing environment: A field laboratory manual. Chapman \& Hall, London.

Cornic, G. and J.M. Briantais. 1991. Partitioning of photosynthetic electron flow between $\mathrm{CO}_{2}$ and $\mathrm{O}_{2}$ reduction in a $\mathrm{C} 3$ leaf (Phaseolus vulgaris L.) at different $\mathrm{CO}_{2}$ concentrations and during drought stress. Planta 183:178-184.

Dai, Y., Z. Shen, Y. Liu, L. Wang, D. Hannaway, and H. Lu. 2009. Effects of shade treatments on the photosynthetic capacity, chlorophyll fluorescence, and chlorophyll content of Tetrastigma hemsleyanum Diels et Gilg. Environ. Expt. Bot. 65:177-182.

Demmig-Adams, B. 1990. Carotenoids and photoprotection in plants: A role for the xanthophyll zeaxanthin. Biochim. Biophys. Acta 1020:1-24.

Gamon, J.A. and R.W. Pearcy. 1990. Photoinhibition in Vitis californica: The role of temperature during high-light treatment. Plant Physiol. 92:487-494.

Genty, B., J.-M. Briantais, and N.R. Baker. 1989. The relationship between the quantum yield of photosynthetic electron transport and quenching of chlorophyll fluorescence. Biochim. Biophys. Acta 990:87-92.

Huang, M. 1995. New ornamental crops in Asia. Acta Hortic. 397:43-58.

Hutchinson, J. 1920. Jeffersonia and Plagiorhegma. Bul. Miscellaneous Info. 7:242-245.

Kong, W.J., J. Wei, P. Abidi, M.H. Lin, S. Inaba, C. Li, Y.L.
Wang, Z.Z. Wang, S.Y. Si, H.N. Pan, S.K. Wang, J.D. Wu, Y. Wang, Z.R. Li, J.W. Liu, and J.D. Jiang. 2004. Berberine is a novel cholesterol-lowering drug working through a unique mechanism distinct from statins. Nature Medicine 10:1344-1351.

Krause, G.H. 1988. Photoinhibition of photosynthesis. An evaluation of damaging and protective mechanisms. Physiol. Plant. 74: 566-574.

Lee, S.Y., S.C. Lee, S.T. Park, J.C. Rhee, T.J. Lee, K.J. Kim, and J.S. Lee. 2008. Effect of shading level of nursing bed on the shoot growth of rooted cuttings in native Hydrangea serrata for. acuminata. Flower Res. J. 16:153-160.

Long, S.P., H. Humphries, and P.G. Falkowski. 1994. Photoinhibition of photosynthesis in nature. Ann. Rev. Plant Physiol. Plant Mol. Biol. 45:633-662.

Maxwell, C., H. Griffiths, A.M. Borland, M.S.J. Broadmeadow, and C.R. McDavid. 1992. Photoinhibitory responses of the epiphytic bromeliad Guzmania monostachia during the dry season in Trinidad maintain photochemical integrity under adverse conditions. Plant Cell Environ. 15:37-47.

Miralles, J., J.J. Martínez-Sánchez, J.A. Franco, and S. Bañón. 2011. Rhamnus alaternus growth under four simulated shade environments: Morphological, anatomical and physiological responses. Sci. Hort. 127:562-570.

National Institute of Environmental Research (NIER). 2004. The conservation strategy for the endangered and reserved plants based on the ecological and genetic characteristics (IV). National Institute of Environmental Research, Korea.

Ögren, E. and M. Sjöström. 1990. Estimation of the effect of photoinhibition on the carbon gain in leaves of a willow canopy. Planta 181:560-567.

Osmond, C. 1994. What is photoinhibition? Some insights from comparisons of shade and sun plants, p. 1-24. In: N.R. Baker and J.R. Bowyer (eds.). Photoinhibition of photosynthesis, from the molecular mechanisms to the field. BIOS Scientific Publ., Oxford.

Pastenes, C., E. Santa-Marı, R. Infante, and N. Franck. 2003. Domestication of the Chilean guava (Ugni molinae Turcz.), a forest understorey shrub, must consider light intensity. Sci. Hortic. 98:71-84.

Reichenauer, T., H.R. Bolar-Nordenkampf, U. Ehrlich, G. Soja, W.F. Postl, and F. Halbwachs. 1997. The influence of ambient and elevated ozone concentrations on photosynthesis in Populus nigra. Plant Cell Environ. 20:1061-1069.

Sorrentino, G., L. Cerio, and A. Alvino. 1997. Effect of shading and air temperature on leaf photosynthesis, fluorescence and growth in lily plants. Sci. Hortic. 69:259-273.

Taiz, L. and E. Zeiger. 2007. Plant physiology. Sinauer Associates, Inc., Publishers, Sunderland, Massachusetts.

Yoo, Y.K. and K.S. Kim. 1997. Effects of shading on the growth in Hibiscus syriacus L. J. Kor. Soc. Hort. Sci. 38:520-526.

You, J.H., Y.H. Jin, H.W. Cho, and C.H. Lee. 2005. Effect of shading ratio on growth of Korean native ferns. Flower Res. J. 13:90-96. 